\title{
Bacterial Contamination in Milk Kitchens in Pediatric Hospitals in Salvador, Brazil
}

\author{
Romilda Castro Cairo $^{1,2}$, Luciana Rodrigues Silva ${ }^{1}$, Carol Ferreira de Andrade ${ }^{1}$, Maria Goreth de Andrade Barberino ${ }^{3}$, Antônio \\ Carlos Bandeira ${ }^{4}$, Kleber Pimentel Santos ${ }^{4}$ and Daniel R. Diniz-Santos ${ }^{1}$ \\ ${ }^{1}$ Pediatric Gastroenterology and Hepatology Service, Professor Hosannah de Oliveira Pediatric Center, Federal University of Bahia; ${ }^{2}$ Medical \\ School, FTC; ${ }^{3}$ Laboratory of Microbiology, Universitary Hospital Prof. Edgard Santos, Federal University of Bahia; Medical and Public Health \\ School of Bahia; Salvador, BA, Brazil
}

\begin{abstract}
Milk may represent an important source of infectious agents to hospitalized pediatric patients. To describe the bacterial microflora isolated from the hands, stools, pharynx of all workers at milk kitchens in pediatric hospitals in the city of Salvador, Brazil, as well as in the formulas prepared by them, we carried out this cross-sectional study with all 91 workers from the 20 milk kitchens of all the public and private hospitals in Salvador, Brazil. Hand and pharynx swabs and stool samples were collected from all workers, as well as samples of the milk and formulas delivered by the kitchens. All samples were cultured for the detection of pathogenic and non-pathogenic bacteria. Pathogenic bacteria were isolated from $20(22.0 \%)$ and $8(8.8 \%)$ cultures of the hands and pharynx of the workers, respectively. No pathogenic bacteria were isolated from stool samples. Pathogenic bacteria were isolated from 17 $\mathbf{( 1 8 . 7 \% )}$ milk samples. The prevalence of pathogenic bacteria in hand swabs was significantly higher in workers from public $(37.8 \%)$ than from private $(6.5 \%)$ hospitals (prevalence ratio $[P R]=5.8 ; p<0.01)$. Pathogenic bacteria were isolated from two $(4.4 \%)$ workers from public hospitals and six $(13.0 \%)$ workers from private hospitals $(P R=0.38$; p=0.27). Pathogenic bacteria were isolated from 11 (24.4\%) milk samples from public hospitals and 6 (13.0\%) from private hospitals $(P R=1.9 ; p=0.16)$. A high prevalence of contamination was found, mainly on the hands of workers on units for manipulation of milk. Preventive efforts should be intensified and focus primarily on effective hand washing and continuous work supervision.
\end{abstract}

Key-Words: Bacteria, microflora, hands, faeces, pharynx, milk, contamination, hospital, children.

In most Brazilian pediatric hospitals, the manipulation of human milk and infant formula occurs in milk kitchens that are independent from the main hospital kitchen. In those units, milk products and their surrogates are prepared and bottled for distribution to hospitalized newborns and suckling infants who are not being exclusively breastfed [1]. Careful hygiene is needed during this process in order to avoid microbial contamination, which could represent a significant threat to patients receiving the milk, who are especially vulnerable to food-borne infectious diseases due to low age and comorbities [2]. Contaminated milk is frequently implicated in hospital food-related outbreaks of gastroenteritis, which is especially worrisome due to the wide distribution of milk in the hospital [1].

Most hospital outbreaks of food-borne infections are caused by foods prepared by the hospital catering service [3]. Those outbreaks are frequently associated with contamination by bacteria such as Staphylococcus aureus, Clostridium spp., Salmonella spp., Yersinia enterocolitica, Shigella spp. and Escherichia coli. Additionally, Enterobacter sakazakii has recently been identified as a pathogenic contaminant of milk [4]. It is possible that the personnel of the hospital catering services are asymptomatic carriers of pathogenic microorganisms and thus represent a continuous source of contamination [5].

Received on 8 December 2007; revised 18 March 2008.

Address for correspondence: Dr. Daniel R. Diniz-Santos. Av. Princesa Isabel, 549, apt. 11, Barra Avenida, Salvador, Bahia, Brazil. Zip code: 40130-030. E-mail: dinizsantosdr@terra.com.br.

The Brazilian Journal of Infectious Diseases 2008;12(3):217-221. (C) 2008 by The Brazilian Journal of Infectious Diseases and Contexto Publishing. All rights reserved.
Contamination of foods may happen at any step from the arrival of the raw goods to the final delivery to the patient. Therefore, good hygiene is crucial throughout the whole process. Hand washing with water and soap is one of the simplest and most effective measures to prevent hospital infection. Alcohol can also be used as a hand sanitizer, preferably after hand washing to complement antisepsis [6].

The aim of this study was to characterize the bacterial flora colonizing the hands, pharynx and faeces of the staff working in milk kitchens in Salvador, the third largest city in Brazil. We also sought bacterial contamination in the milk preparations delivered by those units.

\section{Material and Methods \\ Study Design and Participants}

This is a cross-sectional study in which 91 workers from 20 milk kitchens from 10 public and 10 private hospitals from Salvador, Brazil, were enrolled between February and October, 2006. Only milk kitchens that worked independently from the main hospital kitchen were included in this study.

\section{Collection of Samples}

Samples representative of the microflora from hands, stools and pharynxes of the 91 workers enrolled and from the milk and formula preparations delivered by the 20 milk kitchens studied were collected. Hands and pharyngeal samples were collected by rubbing a swab moistened with sterile saline solution against the skin on the fingers and the pharyngeal mucosa while the participants were on duty. Microbiological samples from the devices used for the preparation and delivery of milk and formula in milk kitchens (blenders, heaters, bottles and spoons) were also collected with a swab. The swabs were 
stored at ambient temperature in Stuart culture media and immediately sent to the bacteriology laboratory. Stools were collected by the workers themselves at home after detailed explanation of the procedure, stored in Cary Blair culture media previously provided by the research team and delivered to a team member in the hospital. Samples of milk and formulas prepared in the kitchens were also collected immediately after preparation, refrigerated at $4^{\circ} \mathrm{C}$ and sent to the laboratory.

\section{Bacteriology}

Hand and pharyngeal samples, as well as milk/formula samples, were incubated in Brain-Heart infusion (BHI) broth and blood- and MacConkey agars at $37^{\circ} \mathrm{C}$ for $24 \mathrm{~h}$. After incubation, BHI broth was inoculated in blood agar at $37^{\circ} \mathrm{C}$ for a further $24 \mathrm{~h}$. Negative cultures at $24 \mathrm{~h}$ were incubated for another $24 \mathrm{~h}$ to confirm the absence of bacterial growth. Suspected colonies were presumptively identified with Gram staining and standard biochemical tests. Stool specimens were inoculated into selenite broth and on MacConkey, SalmonellaShigella (SS) and Karmali agars. MacConkey and SS agar plates were incubated at $37^{\circ} \mathrm{C}$ for $24 \mathrm{~h}$, and selenite broth at $37^{\circ} \mathrm{C}$ for 18h. After incubation, selenite broth was inoculated in SS agar at $37^{\circ} \mathrm{C}$ for $24 \mathrm{~h}$. Suspected colonies were inoculated in EPM-MILI-Citrate medium at $37^{\circ} \mathrm{C}$ for $24 \mathrm{~h}$ for biochemical testing and presumptive identification. After biochemical testing, colonies were tested for serum agglutination with polyvalent sera (Probac) against Shigella sonnei, Shigella flexneri, Shigella boydii and Shigella dysenteriae, classic enteropathogenic E.coli A, B and C, enteroinvasive E. coli A and B, and flagellar and somatic Salmonella antigens. Karmali agar plates were incubated under conditions of microaerophilia at $42^{\circ} \mathrm{C}$. After $48 \mathrm{~h}$, any colonies found were assessed for Campylobacter spp. by Gram staining.

\section{Ethical Considerations}

All hospital managers and workers invited agreed to participate and gave written informed consent. The study protocol was approved by the Research Ethics Committee of our institution.

\section{Statistics}

Continuous variables are presented as mean \pm standard deviation (SD); categorical variables are presented as simple frequencies and proportions. Chi-square and Fisher's exact test were used to compare proportions. Statistical analysis was performed with the Statistical Package for the Social Science (SPSS) version 9.0, Chicago, IL, 1999. Prevalence ratio (PR) was used to evaluate associations. Results were considered statistically significant when $\mathrm{p}=0.05$.

\section{Results}

Ninety-one workers from 20 milk kitchens were enrolled. Forty-six participants worked in private hospitals, while 45 worked in public hospitals. Their demographic characteristics are shown in Table 1.
The most common bacteria isolated from hand samples were coagulase-negative Staphylococcus spp. (63 specimens; 69.2\%), Bacillus spp. (23 specimens; 25.3\%), Pseudomonas spp. (13 specimens; 14.3\%) and Micrococcus spp. (10 specimens; 11.0\%) (Table 2). Pathogenic bacteria (Klebsiella pneumoniae, Enterobacter cloacae, Enterobacter aerogenes, E. coli, Proteus mirabilis, Klebsiella oxytoca, Serratia spp. and Citrobacter freundii) were isolated from 20 (22.0\%) hand samples. Interestingly, 17 of those 20 samples belonged to workers from public hospitals, yielding a prevalence of pathogenic bacteria of 37.8\% in workers from public hospitals compared to $6.5 \%$ in workers from private hospitals and a prevalence ratio (PR) of $5.8(\mathrm{p}=0.0003)$ (Figure 1$)$.

The most prevalent bacteria in pharyngeal samples were Streptococcus alpha-gamma hemolytic (78 specimens; 85.7\%), coagulase-negative Staphylococcus spp. (42 specimens; 46.2\%), Neisseria spp. (36 specimens; 39.6\%) and Bacillus coryneform (16 specimens; 17.6\%). Pathogenic bacteria (Pseudomonas aeruginosa, Klebsiella pneumoniae, Serratia spp. and group A beta-hemolytic Streptococcus pyogenes) were found in 8 pharyngeal samples (8.8\%), two of which were from caterers in public hospitals and the remaining six from private hospitals (Table 3 ). As a consequence, the prevalence of pharyngeal colonization by pathogenic bacteria was $4.4 \%$ in caterers in public hospitals and $13.0 \%$ in private hospitals ( $\mathrm{PR}=0.38 ; \mathrm{p}=0.27$ ) (Figure 2). Pathogenic bacteria were not found in any stool culture.

The bacteria isolated from milk and formula samples were most often Bacillus spp. (28 samples; 30.8\%), coagulasenegative Staphylococcus spp. (12; 13.2\%) and Pseudomonas spp. (7; 7.7\%). Pathogenic bacteria (Klebsiella pneumoniae, Enterobacter cloacae, Enterobacter aerogenes, Serratia spp., Citrobacter freundii, Stenotrophomonas maltophilia and Pseudomonas aeruginosa) were found in 17 (18.7\%) samples of milk/formula. The rate of contamination was $24.4 \%$ in public hospitals and $13.0 \%$ in private hospitals $(P R=1.9$; $\mathrm{p}=0.16)$. Bacteria isolated from milk and formula samples prepared in milk kitchens from public and private hospitals are shown in Table 4.

Cultures of the samples from the devices used by the milk kitchens isolated several pathogenic bacteria, highlighting Klebsiella pneumoniae (3; 11.1\%), Escherichia coli (2; $7.4 \%)$, Citrobacter freundii $(1 ; 3.7 \%)$ and Stenotrophomonas maltophilia (1; 3.7\%). We observed that 3 (24.9\%) devices from the public kitchens were colonized by more than one pathogenic bacteria, while only 1 (8.3\%) device from the private kitchens was colonized by pathogenic bacteria $(\mathrm{PR}=3.0 ; \mathrm{p}=0.59)$.

\section{Discussion}

Resident microflora has a characteristic low virulence and very rarely causes disease in healthy individuals, but it may cause systemic infection after invasive procedures and in immunocompromised patients and newborns. In this context, the high prevalence of colonization by coagulase- 
Table 1. Characteristics of 91 workers in milk kitchens enrolled from 20 hospitals in Salvador, Brazil.

\begin{tabular}{lrr}
\hline Age $(\mathrm{yr})$ & $37.98 \pm 7.71 \mathrm{yrs}$ \\
$\quad$ Median & & $39 \mathrm{yrs}$ \\
$\quad$ Range & & $22-61 \mathrm{yrs}$ \\
Education & 13 & {$[14.3 \%]$} \\
$\quad$ Elementary school & 74 & {$[81.3 \%]$} \\
$\quad$ High school & 1 & {$[1.1 \%]$} \\
$\quad$ College & 3 & {$[3.3 \%]$} \\
$\quad$ Others & & \\
Color of the skin & 2 & {$[2.2 \%]$} \\
$\quad$ White & 58 & {$[63.8 \%]$} \\
$\quad$ Intermediate & 31 & {$[34.1 \%]$} \\
$\quad$ Black & & \\
\hline
\end{tabular}

Figure 1. Frequency of pathogenic and non-pathogenic bacteria isolated from the hands of workers in milk kitchens in private and public hospitals in Salvador, Brazil.

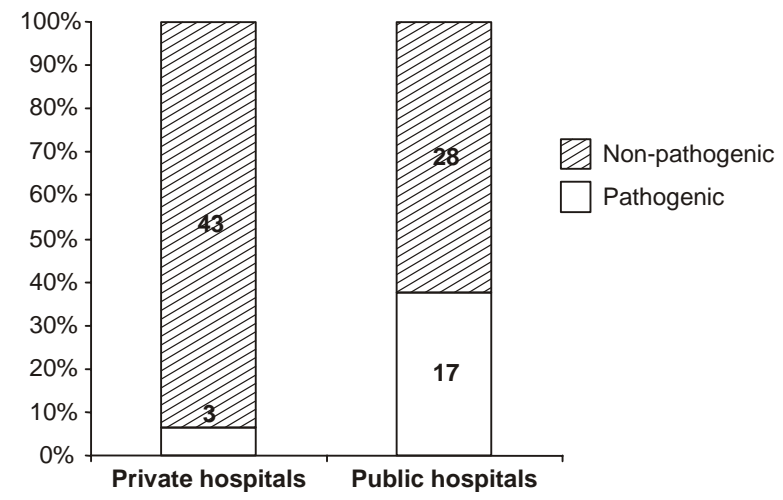

Table 2. Bacteria isolated from hand samples of workers from milk kitchens in public and private pediatric hospitals in Salvador, Brazil.

\begin{tabular}{|c|c|c|c|c|c|c|}
\hline \multirow[t]{2}{*}{ Bacteria } & \multicolumn{2}{|c|}{$\underline{\text { Private hospitals }}$} & \multicolumn{2}{|c|}{ Public hospitals } & \multicolumn{2}{|c|}{ All hospitals } \\
\hline & $\mathbf{N}$ & $\%$ & $\mathbf{N}$ & $\%$ & $\overline{\mathbf{N}}$ & $\%$ \\
\hline Coagulase - negative Staphylococcus spp. & 30 & 65.2 & 33 & 73.3 & 63 & 69.2 \\
\hline Staphylococcus aureus & 6 & 13.0 & 3 & 6.7 & 9 & 9.9 \\
\hline Bacillus spp. & 10 & 21.7 & 13 & 28.9 & 23 & 25.3 \\
\hline Pseudomonas spp. & 4 & 8.7 & 9 & 20.0 & 13 & 14.3 \\
\hline Pseudomonas aeruginosa & 1 & 2.2 & 1 & 2.2 & 2 & 2.2 \\
\hline Micrococcus spp. & 4 & 8.7 & 6 & 13.3 & 10 & 11.0 \\
\hline Alpha-gamma hemolytic Streptococcus & 4 & 8.7 & 1 & 2.2 & 5 & 5.5 \\
\hline Bacillus coryneform & - & - & 3 & 6.7 & 3 & 3.3 \\
\hline Klebsiella pneumoniae & 1 & 2.2 & 6 & 13.3 & 7 & 7.7 \\
\hline Klebsiella oxytoca & - & - & 1 & 2.2 & 1 & 1.1 \\
\hline Enterobacter cloacae & - & - & 2 & 4.4 & 2 & 2.2 \\
\hline Enterobacter aerogenes & - & - & 3 & 6.7 & 3 & 3.3 \\
\hline E. coli & 1 & 2.2 & 2 & 4.4 & 3 & 3.3 \\
\hline Proteus mirabilis & - & - & 1 & 2.2 & 1 & 1.1 \\
\hline Citrobacter freundii & - & - & 2 & 4.4 & 2 & 2.2 \\
\hline Serratia spp. & - & - & 3 & 6.7 & 3 & 3.3 \\
\hline
\end{tabular}

Figure 2. Frequency of pathogenic and non-pathogenic bacteria isolated from the pharynx of workers in milk kitchens in private and public hospitals in Salvador, Brazil.

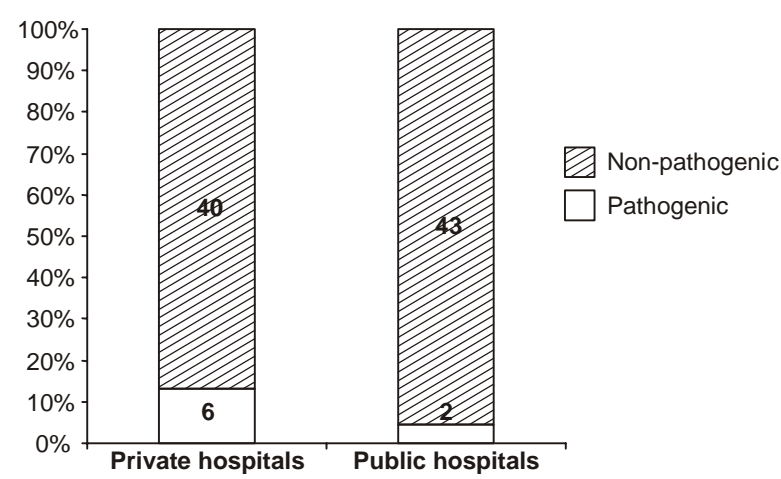

Figure 3. Frequency of pathogenic and non-pathogenic bacteria isolated from milk and formulas delivered by milk kitchens in public and private hospitals in Salvador, Brazil.

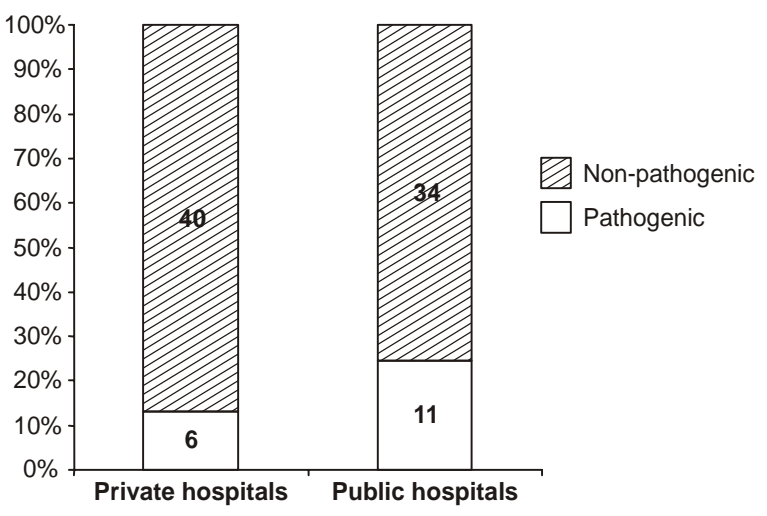


Table 3. Bacteria isolated from pharyngeal samples of workers from milk kitchens in public and private pediatric hospitals in Salvador, Brazil.

\begin{tabular}{|c|c|c|c|c|c|c|}
\hline \multirow[t]{2}{*}{ Bacteria } & \multicolumn{2}{|c|}{ Private hospitals } & \multicolumn{2}{|c|}{ Public hospitals } & \multicolumn{2}{|c|}{ All hospitals } \\
\hline & $\mathbf{N}$ & $\%$ & $\mathbf{N}$ & $\%$ & $\mathbf{N}$ & $\%$ \\
\hline Coagulase - negative Staphylococcus spp. & 20 & 43.5 & 22 & 48.9 & 42 & 46.2 \\
\hline Staphylococcus aureus & 7 & 15.2 & 6 & 13.3 & 13 & 14.3 \\
\hline Bacillus spp. & 1 & 2.2 & 2 & 4.4 & 3 & 3.3 \\
\hline Pseudomonas spp. & 1 & 2.2 & - & - & 1 & 1.1 \\
\hline Pseudomonas aeruginosa & 2 & 4.3 & - & - & 2 & 2.2 \\
\hline Micrococcus spp. & 1 & 2.2 & 1 & 2.2 & 2 & 2.2 \\
\hline Alpha-gamma hemolytic Streptococcus & 39 & 84.8 & 39 & 86.7 & 78 & 85.7 \\
\hline Bacillus coryneform & 7 & 15.2 & 9 & 20.0 & 16 & 17.6 \\
\hline Klebsiella pneumoniae & 1 & 2.2 & 2 & 4.4 & 3 & 3.3 \\
\hline Serratia spp. & 1 & 2.2 & - & - & 1 & 1.1 \\
\hline Neisseria spp. & 17 & 37.0 & 19 & 42.2 & 36 & 39.6 \\
\hline Streptococcus pneumoniae & 1 & 2.2 & - & - & 1 & 1.1 \\
\hline Group A beta-hemolytic Staphylococcus pyogenes & es 2 & 4.3 & - & - & 2 & 2.2 \\
\hline Candida spp. & - & - & 1 & 2.2 & 1 & 1.1 \\
\hline Enterococcus spp. & - & - & 1 & 2.2 & 1 & 1.1 \\
\hline Group D Enterococcus & 1 & 2.2 & - & - & 1 & 1.1 \\
\hline Haemophilus spp. & 2 & 4.3 & - & - & 2 & 2.2 \\
\hline
\end{tabular}

Table 4. Bacteria isolated from milk and formulas delivered by milk kitchens in public and private hospitals in Salvador, Brazil.

\begin{tabular}{|c|c|c|c|c|c|c|}
\hline \multirow[t]{2}{*}{$\overline{\text { Bacteria }}$} & \multicolumn{2}{|c|}{ Private hospitals } & \multicolumn{2}{|c|}{ Public hospitals } & \multicolumn{2}{|c|}{ All hospitals } \\
\hline & $\mathbf{N}$ & $\%$ & $\mathbf{N}$ & $\%$ & $\mathbf{N}$ & $\%$ \\
\hline Bacillus spp. & 13 & 28.3 & 15 & 33.3 & 28 & 30.8 \\
\hline Coagulase - negative Staphylococcus spp. & 7 & 15.2 & 5 & 13.3 & 12 & 13.2 \\
\hline Pseudomonas spp. & 2 & 4.3 & 5 & 8.9 & 7 & 7.7 \\
\hline Klebsiella pneumoniae & 3 & 6.5 & 3 & 6.7 & 6 & 6.6 \\
\hline Alpha-gamma hemolytic Streptococcus & 2 & 4.3 & 4 & 8.7 & 6 & 6.6 \\
\hline Enterobacter aerogenes & - & - & 5 & 11.1 & 5 & 5.5 \\
\hline Pseudomonas aerogenes & 2 & 4.3 & 3 & 6.7 & 5 & 5.5 \\
\hline Chromobacterium violaceum & 2 & 4.3 & - & - & 2 & 2.2 \\
\hline Staphylococcus aureus & 1 & 2.2 & 1 & 2.2 & 2 & 2.2 \\
\hline Cedecea spp. & - & - & 1 & 2.2 & 1 & 1.1 \\
\hline Citrobacter freundii & 1 & 2.2 & - & - & 1 & 1.1 \\
\hline Enterobacter cloacae & 1 & 2.2 & - & - & 1 & 1.1 \\
\hline Group D Enterococcus & 1 & 2.2 & - & - & 1 & 1.1 \\
\hline Serratia spp. & 1 & 2.2 & - & - & 1 & 1.1 \\
\hline Stenotrophomonas maltophilia & - & - & 1 & 2.2 & 1 & 1.1 \\
\hline
\end{tabular}

negative Staphylococcus spp. is expected since this rod is normally found on hand microflora. Staphylococcus aureus can also be found as a component of the resident microflora on hands and in the nose, but it is also a major etiologic agent of skin infections and can easily contaminate foods manipulated by infected or colonized caterers [7]. Several other studies have reported prevalence rates of $S$. aureus colonization similar to the one herein reported (9.9\%) [8-10].
Bacillus spp. is not present as resident microflora, but it may be found as transient flora in consequence to faecal contamination [11]. The isolation of Bacillus spp. from the hand samples of $25.3 \%$ of the participants of this study depicts inadequate hand washing before and during duty hours. All enterobacteria isolated (E.coli, Proteus mirabilis, Klebsiella pneumoniae, Klebsiella oxytoca, Enterobacter cloacae, Enterobacter aerogenes, Citrobacter freundii, Serratia spp.) are part of the transient microflora of the hands and are 
promptly eliminated when hands are adequately washed with soap or $70 \%$ alcohol. Therefore, they should not be present on the hands of the caterers during the manipulation of milk. Their detection suggests recent contamination of hands with faecal material, indicating poor compliance with basic hygiene principles such as hand washing. The finding of Pseudomonas spp e Pseudomonas aeruginosa on the hands of those caterers is especially worrisome given their high likelihood of causing infections.

The prevalence of colonization by enteropathogens was significantly higher in individuals working in public hospitals, which may be due to ineffective supervision or to inadequate training. This study, however, was not designed to address that question and further studies on that topic are warranted.

Although enterobacteria were less prevalent in pharyngeal samples, the prevalence of $S$. aureus must be stressed because of the importance of identifying and controlling their carriers who are working in catering services due to the existence of enterotoxin-producing strains [12]. In contrast to the findings from the hand sample cultures, there was no significant difference between the prevalence of pathogenic bacteria colonizing the pharynx of workers in public and private hospitals.

Stool cultures have not identified the presence of any enteropathogen, which is in accordance with the findings of Sales \& Goulart [10], but in contrast to the findings of Alicia et al., who reported a prevalence of $20.0 \%$ of asymptomatic Salmonella carriage among the caterers of a milk processing unit in Medellin, Colombia [13]. Given the high prevalence of asymptomatic carriage of enteropathogens and the consequently enhanced risk of food contamination, the American Hospital Association recommends that individuals working in hospital catering services have their stools routinely cultured every three months [1].

We could document that many workers in milk kitchens, especially in public hospitals, are not washing their hands adequately, exposing the patients, who receive the foods prepared by them, to unnecessary risks of acquiring infections that may present enhanced severity due to patients' immune immaturity. As a consequence, the effective training of those professionals and the use of protective equipments such as gowns, gloves, masks and caps are paramount.

\section{References}

1. American Hospital Association. Funcionamento e planejamento de lactários, 1st edition, American Hospital Association 1983.

2. ANVISA. Curso Básico de Controle de Infecção Hospitalar. Caderno e Programa do Controle de Infecção Hospitalar. Brasília: Brazilian Ministry of Health 2000.

3. Bryan F.L. Hazard analysis critical control point (HACCP) systems for retail food and restaurant operations. J Food Protection 1990;53:978-83.

4. WHO/FAO. Workshop on Enterobacter sakasakii and other microorganisms in powder infant formulas. Geneve: World Health Organization 2004.

5. Vanetti M.C., Pinto U.M. Detecção de Listeria, Salmonella e Klebsiella em serviço de alimentação hospitalar. Rev Nutr 2004;17:319-26.

6. Brazilian Ministry of Health. Programa de controle de infecção hospitalar. Lavar as mãos: Informações para profissionais de saúde. Brasilia: Brazilian Ministry of Health 1989.

7. Tortora G.J., Case C.L. (eds). Microbiologia. 6th edition. Porto Alegre: Artmed 2000.

8. Andrade G.P., Zelante F. Ocorrência simultânea de Staphylococcus aureus enterotoxigênicos nas mãos, boca e fezes em portadores assintomáticos. Rev Saude Publica 1989;23:277-84.

9. Santos B.M.O., Tanaka A.M.V. Prevalência de portadores sãos de Staphylococcus aureus em pessoal de diferentes categorias de enfermagem de um hospital geral escola. Medicina 1989;22:118.

10. Salles R.K., Goulart R. Diagnóstico das condições higiênicosanitárias e microbiológicas de lactários hospitalares. Rev Saude Publica 1997;31:131-9.

11. Ghelardi E., Celandroni F., Salvetti S., et al. Identification and characterization of toxigenic Bacillus cereus isolates responsible for two food- poisoning outbreaks. FEMS Microbiology Letters 2002;208:129-34.

12. Iaria S.T., Furlanetto S.M.P., Cerqueira Campos M.L. Pesquisa de Staphylococcus aureus enterotoxigênico nas fossas nasais de manipuladores de alimentos em hospitais. Rev Saude Publica 1980;19:93-100.

13. Alicia A.D.E., Puerta E.C. Estudio integral del servicio del lactário de la Clínica Leon XIII - ISS Medellin. Medellin: Escola Nacional de Saude Publica, 1977. 